\section{The Relationship between Duration of Infertility and Intrauterine Insemination: A Multi-Centers Study}

\section{Abstract}

Introduction: The duration of infertility should be considered as a factor that may affect the outcome of Assisted Reproductive Techniques (ART). The aim of the present work is to examine the outcome of infertility treatment in relation to duration of infertility.

Materials and methods: One hundred fifty-two couples with mild male infertility factor were involved in this retrospective study. Sixty nine couples from Allow In vitro Fertilization center (IVF), and remaining (83 couples) from Embryo Research and Infertility Treatment; Al-Nahrain University, Baghdad-Iraq. Intrauterine Insemination (IUI) had been done for all couples using the same ART.

Results: The mean age of men was $35.88 \pm 0.57$ years and the duration of infertility was $5.44 \pm 0.29$ year (range=1-19 years). The higher pregnancy and life-birth rates was demonstrated in those couples suffering from infertility for duration less than 4 years in compare to those who had duration more than 10 years $(P<0.003$, $r=-0.869$ ). Abortion rate was observed in those couples who had duration more than 10 years in compare to those who have duration of infertility less than 4 years $(P<0.0014)$. The linear life-birth rate, in both IVF centers, shows decrease by increase in the duration of infertility.

Conclusion: The researchers conclude that by increase in the duration of infertility the outcome of assisted reproductive techniques -IUI will be decreased markedly.

Keywords: Infertility; ART; IUI; Life birth rate
Ahmed K. Allow' ${ }^{1}$, Sadek S. M. Abdulmogny A², Bracamonte Maryam ${ }^{3}$, Khilood Naji Ghafouri AlAni ${ }^{4}$, Muhammed-Baqir Fakhrildin ${ }^{4}$ and Wael Muhamad'

1 Department of Basic Medical Science, Kulliyyah of Medicine, International Islamic University, Malaysia

2 Department of Physiology, Faculty of Medicine and Health Sciences, Sana'a University, Yemen

3 Allow IVF Center Sana'a, Yemen

4 Institute of Embryo Research and Infertility Treatment, Al-Nahrain University, Baghdad, Iraq

Corresponding author: Allow AK

”Ivf2007@gmail.com

Department of Basic Medical Science, Kulliiyyah of Medicine, International Islamic University Malaysia, Malaysia.

Tel: 60177772162

Citation: Allow AK, Abdulmogny SMAA, Maryam B, et al. The Relationship between Duration of Infertility and Intrauterine Insemination: A Multi-Centers Study. J Clin Dev Biol. 2016, 1:3.

nevertheless need more complex medical intervention like ARTs which is referred to many methods designed to overcome barriers to natural fertilization [7]. Over all, the estimated number of infertile patients treated by ART is around $20 \%$. The goal is to increase the success rate of ART both in term of achieving pregnancy and in making sure that the pregnancy result in a genetically healthy individual [8].

The duration of infertility should be considered as a factor that may affect the outcome of ART. It is unclear the effect of duration
Several methods for treatment of infertility are depending on the underlying cause of infertility [6]. Some infertile couples 
of infertility on the outcome of infertility treatment especially semen characteristics of infertile males undergoing IUI, and this subject, in general, is not completely understood. We aimed to examine, retrospectively, the outcome of infertility treatment in relation to duration of infertility in infertile couples. From another point, performing this retrospective analysis of data in two different places (multi-central study) is the second goal of this study to give more confidence as well as evidences for the obtained results.

\section{Materials and Methods}

One hundred fifty-two couples with mild male infertility factor of different age and duration of infertility were involved in this retrospective study. Sixty nine couples form Allow IVF Center, Sana'a Yemen, and remaining (83 couples) from Embryo Research and Infertility Treatment; Al-Nahrain University, Baghdad-Iraq. The duration of this study was from 2019 to 2013. All males were evaluated by the male infertility consultant and completed history as well as clinical examination. Semen sample was obtained by masturbation with collection of the ejaculate into a clean, dry, sterile and wide mouthed Petri-dish; this was done after 3-5 days of abstinence. The container was labeled with date and time, names of patient and his wife, and their file number. The sample was transported to the laboratory immediately and placed in an incubator at $37^{\circ} \mathrm{C}$ till complete liquefaction. A drop of $10 \mu \mathrm{L}$ of liquefied and thoroughly mixed semen was taken by Eppendorff automatic pipette, mounted between warm slides and covered with a standard cover slip $(22 \times 22) \mathrm{mm}$. The sample was scored by light microscope under magnification of $40 \mathrm{X}$ objectives. The semen was analyzed macroscopically and microscopically using the standardization of World health Organization [9].

The male factor infertility had been treated by conventional treatment of male infertility and involved in the ART. IUI was done for all couples involved in the present study using the same ART [3]. The overall outcome of this treatment had been analyzed in correlation with their duration of infertility.

\section{Statistical analysis}

Standard statistical methods were used for data analysis to determine mean, standard deviation and Standard Error of Mean (SEM), a typical type of students paired T-test, Chi-square, and Kruskal-Wallis one-way analysis of variance. Correlation coefficients were calculated according to Pearson. Data were analyzed using Statistical Package for the Social Sciences SPSS 20.5 (Inc. Chicago, IL). A power of measurement was considered more than $80 \%$ and $P$-value of $<0.05(P<0.05)$ was as well considered statistically significant.

\section{Ethical approval}

Protocol of the present study was conducted in compliance with human care standards outcome of Allow IVF center and Ethics Committee of Faculty of Medicine and Health Sciences Sana'a University and Embryo Research and Infertility Treatment; AlNahrain University, Baghdad-Iraq.

\section{Results}

One hundred fifty two infertile males were involved in the current study with the mean age of $35.88 \pm 0.57$ years. The mean duration of infertility of them was $5.44 \pm 0.29$ years with range of 1-19 years. The semen samples had been obtained from infertile males and Seminal Fluid Analysis (SFA) was done depending on WHO recommended criteria.

In this study, the percentage of infertile couples with secondary infertility was $76 \%$ (Figure 1).

Results of the present study showed that the largest division of infertile males were within age group (30-39) years (no. 90; $57.6 \%)$. The second degree was occupied by the infertile males within age group (40-49) years (no. $35 ; 22.4 \%)$. However, the smallest group was within age group $\geq 50$ years (no. $6 ; 3.2 \%$ ) (Figure 2).

Table 1 shows the parameters of SFA for infertile males classified according to age group. It was noticed that the best sperm concentration (million/mL) was within the two age groups (30-

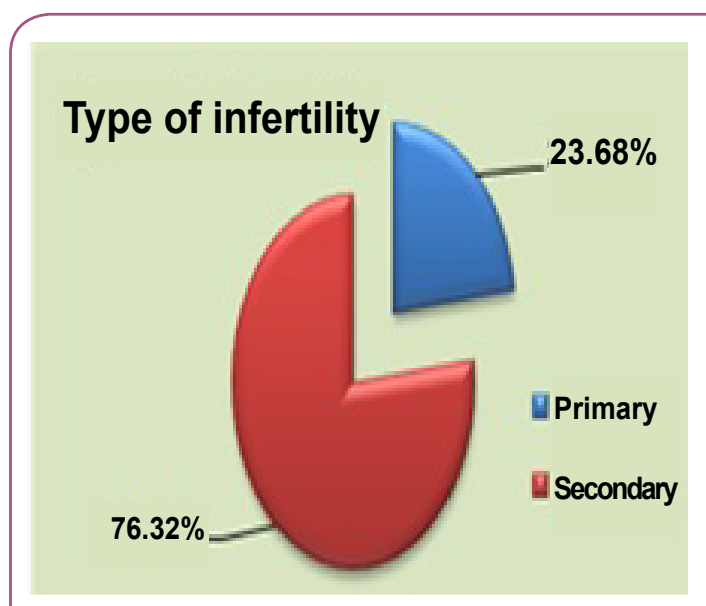

Figure 1 Number of infertile males classified according to type of infertility.

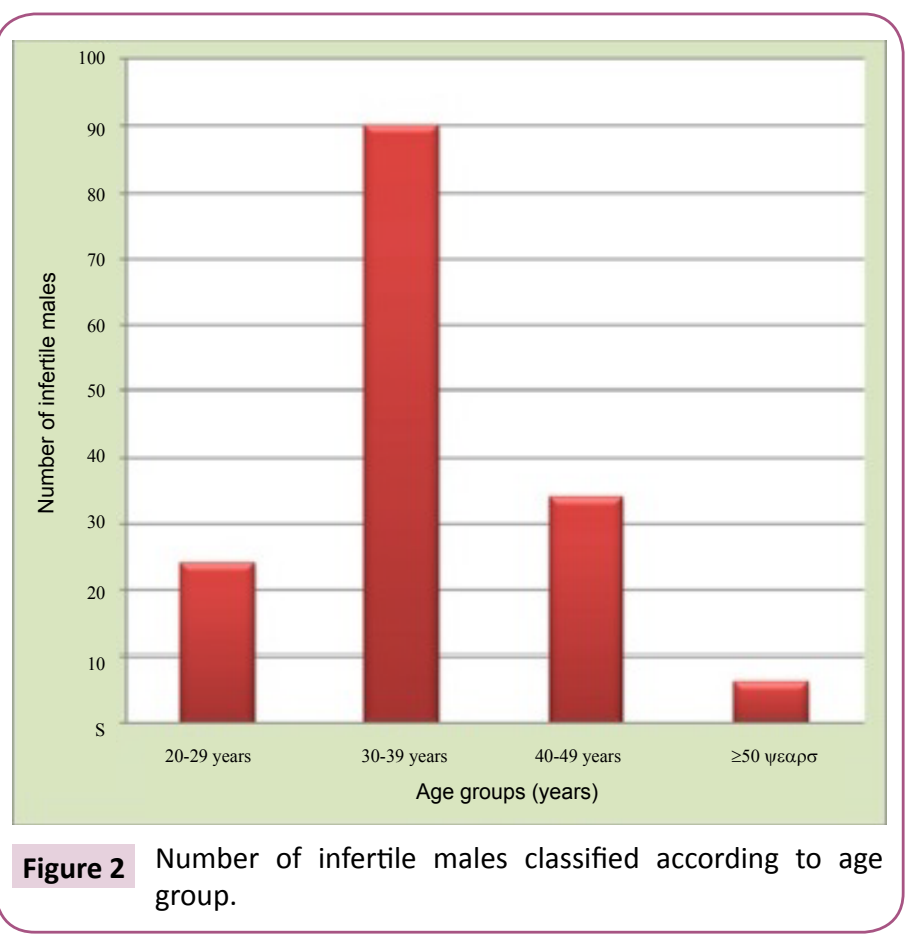


Table 1 Sperm parameters for infertile males classified according to age group.

\begin{tabular}{|c|c|c|c|c|c|}
\hline \multicolumn{2}{|c|}{ Sperm parameters } & $\begin{array}{l}\text { 20-29 years } \\
\text { No. } 25\end{array}$ & $\begin{array}{l}\text { 30-39 years } \\
\text { No. } 90\end{array}$ & $\begin{array}{l}\text { 40-49 years } \\
\text { No. } 35\end{array}$ & $\begin{array}{l}>50 \text { years } \\
\text { No. } 6\end{array}$ \\
\hline \multicolumn{2}{|c|}{$\begin{array}{l}\text { Sperm concentration } \\
(\text { million } / \mathrm{mL})\end{array}$} & $33.88 \pm 2.49$ & $43.29 \pm 1.57$ & $45.11 \pm 2.83$ & $34.17 \pm 5.23$ \\
\hline \multicolumn{2}{|c|}{ Sperm motility (\%) } & $56 \pm 2.89$ & $65 \pm 1.37$ & $63.69 \pm 3.01$ & $57.5 \pm 4.43$ \\
\hline \multirow{4}{*}{$\begin{array}{c}\text { Sperm grade activity } \\
\text { (\%) }\end{array}$} & A & $3.4 \pm 1.31$ & $6.78 \pm 1.06$ & $10.23 \pm 2.13$ & $0.83 \pm 0.83$ \\
\hline & B & $29.2 \pm 2.91$ & $34.94 \pm 1.24$ & $30.91 \pm 2.3$ & $25.83 \pm 6.11$ \\
\hline & C & $23.4 \pm 1.73$ & $23.5 \pm 1.01$ & $22.29 \pm 1.61$ & $30.83 \pm 3.27$ \\
\hline & D & $43.6 \pm 2.85$ & $34.78 \pm 1.31$ & $36 \pm 3.02$ & $42.5 \pm 4.43$ \\
\hline \multicolumn{2}{|c|}{ Progressive sperm motility (\%) } & $32.6 \pm 2.92$ & $41.78 \pm 1.6$ & $41.14 \pm 3.22$ & $26.67 \pm 6.54$ \\
\hline \multicolumn{2}{|c|}{ Normal sperm morphology (\%) } & $44.6 \pm 2.31$ & $52.37 \pm 1.5$ & $46.97 \pm 2.45$ & $40 \pm 2.58$ \\
\hline \multicolumn{2}{|c|}{ Sperm agglutination (\%) } & $6.52 \pm 1.55$ & $8.22 \pm 1.14$ & $12.03 \pm 2.33$ & $5 \pm 3.42$ \\
\hline \multicolumn{2}{|c|}{ Round cells count } & $4.56 \pm 1.1$ & $5.46 \pm 0.71$ & $7.11 \pm 1.36$ & $10.5 \pm 4.99$ \\
\hline
\end{tabular}

Data are Mean \pm SED

Total number of infertile males $=152$

39) years (43.29 \pm 1.57$)$ and age group (40-49) years (45.11 \pm 2.83). Regarding the percentage of sperm motility, best results were obtained within the same two age groups (30-39) years (65 $\pm 1.37)$ and (40-49) years (63.69 \pm 3.01$)$. A significant difference $(P<0.05)$ was observed in the percentage of progressive sperm motility grade $(A)$, the best results were noticed among age group $(40-49)$ years $(10.23 \pm 2.13)$ and the lowest values were in the age group $\geq 50$ years $(0.83 \pm 0.83)$. The best results regarding the percentage of progressive sperm motility grade (B) were noticed in the age group (30-39) years $(34.94 \pm 1.24)$ and the lowest values were in age group $\geq 50$ years $(25.83 \pm 6.11)$. The overall percentage of sperm progressive motility (grade $A+B$ ) showed a significant difference $(P<0.01)$ with highest percentage in age groups (30-39) years $(41.78 \pm 1.6),(40-49)$ years $(41.14 \pm 3.22)$ and the lowest value was among age group $\geq 50$ years $(26.67 \pm$ 6.54). Furthermore there was a significant difference $(P<0.01)$ regarding the percentage of normal sperm morphology. However, the highest results were within age group (30-39) years (52.37 \pm $1.5)$ compared with the lowest results in the age group $\geq 50$ years (40 \pm 2.58).

DE Numbers of infertile males classified according to duration of infertility were observed in Figure 3. It was clear that the largest group of infertile males was with duration of infertility 3-4 years (no. $52 ; 33.3 \%$ ), then the group with duration of infertility $5-6$ years (no. 37; 22.4\%). The smallest group (no. 9; 5.7\%) was being observed for infertile males with duration of infertility $\geq 10$ years. Although little variations were assessed for seminal fluid parameters among different groups of infertile males classified according to duration of infertility (Table 2), but it was observed that the percentage of sperm progressive motility grade $(A+B)(32.22 \pm 6.62)$ and percentage of normal sperm morphology $(44.78 \pm 5.43)$, were the lowest among the group with duration of infertility $>11$ years. Moreover, the percentage of sperm agglutination (12.22 \pm 4.34$)$ and assessed counts of round cells $(6.33 \pm 2.58)$ were with highest results in the group of $>11$ years duration of infertility.

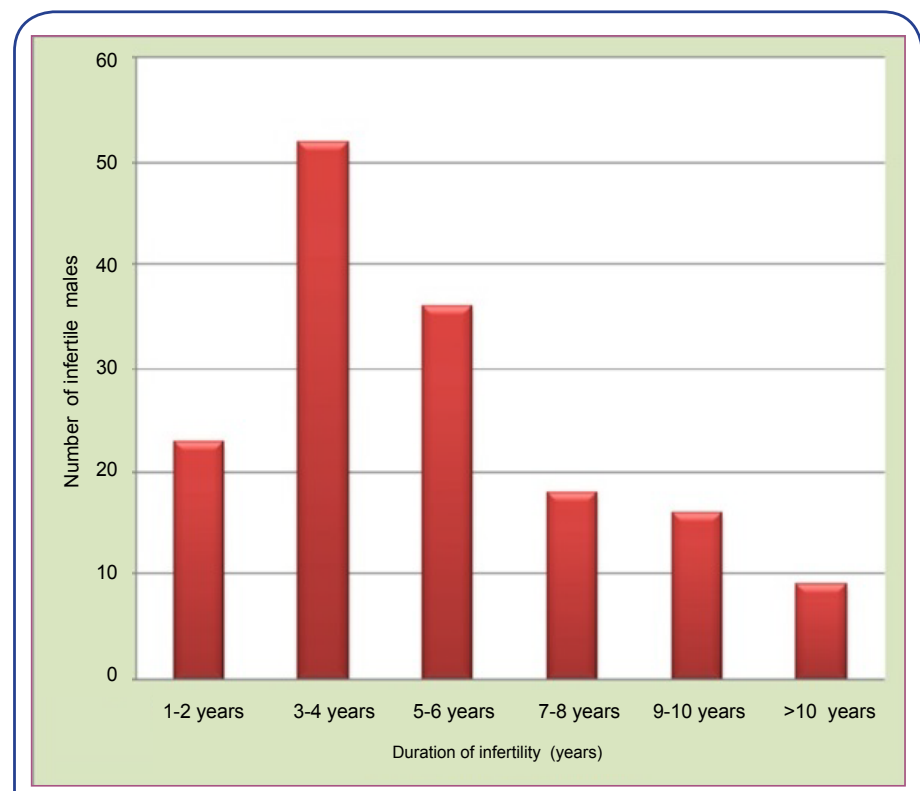

Figure 3 Number of infertile males classified according to duration of infertility.

The outcome of assisted reproductive technologies, IUI for infertile males treated for infertility including pregnancy, life birth and abortion rates had been demonstrated in the Figure 4. The higher pregnancy and life-birth rates had been demonstrated in those males suffering from infertility for duration less than 4 years in compare to those who had duration more than 10 years $(P<0.003, r=-0.869)$. Abortion rate had been observed in those men who had duration more than 10 years in compare to those who had duration of infertility less than 4 years $(P<0.0014)$.

The relationship between duration of infertility and results of ART -IUI in males involved in the present study from Iraq $(n=83)$ and Yemen $(n=69)$ demonstrates in Figures 5 and 6 respectively. The linear life-birth rate, in both IVF centers, shows decrease by increase in the duration of infertility. 
Table 2 Sperm parameters for infertile males classified according to duration of infertility.

\begin{tabular}{|c|c|c|c|c|c|c|c|}
\hline \multicolumn{2}{|c|}{ Sperm parameters } & $\begin{array}{c}\text { 1-2 years } \\
\text { No. } 22\end{array}$ & $\begin{array}{c}\text { 3-4 years } \\
\text { No. } 47\end{array}$ & $\begin{array}{c}\text { 5-6 years } \\
\text { No. } 32\end{array}$ & $\begin{array}{c}\text { 7-8 years } \\
\text { No. } 15\end{array}$ & $\begin{array}{c}\text { 9-10 years } \\
\text { No. } 17\end{array}$ & $\begin{array}{c}>10 \text { years } \\
\text { No. } 19\end{array}$ \\
\hline \multicolumn{2}{|c|}{ Sperm concentration (million/mL) } & $42.58 \pm 3.77$ & $42 \pm 1.86$ & $41.89 \pm 2.33$ & $40.22 \pm 5.02$ & $42.13 \pm 3.19$ & $32.33 \pm 4.25$ \\
\hline \multicolumn{2}{|c|}{ Sperm motility (\%) } & $62.08 \pm 2.31$ & $64.31 \pm 1.66$ & $63.89 \pm 2.3$ & $61.11 \pm 4.78$ & $63.44 \pm 4.49$ & $45 \pm 6.87$ \\
\hline Sperm grade & A & $6.25 \pm 1.48$ & $5.67 \pm 1.17$ & $7.44 \pm 1.8$ & $8.33 \pm 3.79$ & $7.5 \pm 2.96$ & $4.22 \pm 3.45$ \\
\hline \multirow{2}{*}{ activity } & B & $34.17 \pm 2.23$ & $34.71 \pm 1.73$ & $32 \pm 2.07$ & $30 \pm 3.68$ & $32.19 \pm 3.32$ & $25 \pm 4.93$ \\
\hline & C & $21.67 \pm 1.72$ & $23.94 \pm 1.25$ & $24.17 \pm 1.68$ & $23.89 \pm 2.64$ & $23.75 \pm 2.44$ & $22.78 \pm 2.9$ \\
\hline (\%) & D & $37.92 \pm 2.31$ & $35.48 \pm 1.63$ & $35.83 \pm 2.3$ & $37.78 \pm 4.32$ & $36.56 \pm 4.49$ & $45 \pm 6.87$ \\
\hline \multicolumn{2}{|c|}{ Progressive sperm motility (\%) } & $39.58 \pm 2.79$ & $40.87 \pm 1.92$ & $39.44 \pm 2.75$ & $38.33 \pm 5.59$ & $39.69 \pm 4.29$ & $32.22 \pm 6.62$ \\
\hline \multicolumn{2}{|c|}{ Normal sperm morphology } & $47.83 \pm 2.71$ & $50.12 \pm 1.62$ & $51.25 \pm 1.83$ & $51.94 \pm 4.84$ & $45.31 \pm 4.71$ & $44.78 \pm 5.43$ \\
\hline \multicolumn{2}{|c|}{ Sperm Agglutination (\%) } & $9.43 \pm 3.11$ & $8.2 \pm 1.53$ & $8.49 \pm 1.38$ & $7.11 \pm 2.25$ & $8.93 \pm 3.02$ & $12.22 \pm 4.34$ \\
\hline \multicolumn{2}{|c|}{ Round cells count } & $5.04 \pm 1.84$ & $6.9 \pm 1.05$ & $5.61 \pm 0.96$ & $3.83 \pm 1.47$ & $5.27 \pm 1.18$ & $6.33 \pm 2.58$ \\
\hline
\end{tabular}

Data are Mean \pm SEM

Total number of infertile males $=152$

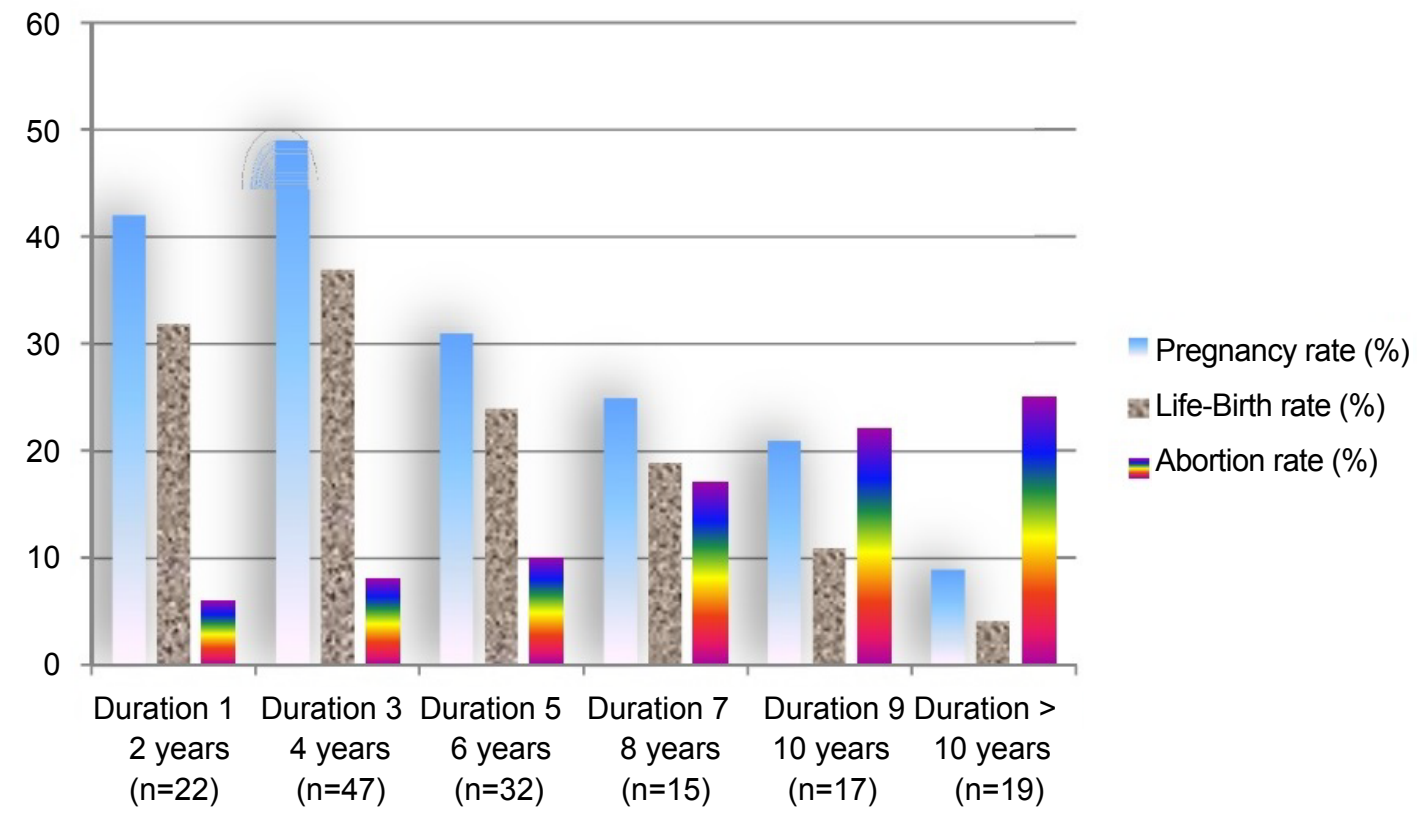

Figure 4 Pregnancy, life-birth and abortion rates, after IUI, among infertile males according to duration of infertility.

\section{Discussion}

The results of this study showed that the secondary infertility was more than three times as the primary infertility. This is in a good agreement with that results published by another researchers $[10,11]$. This was in disagreement with the results of this study because the couples who involved in this study, had visited us asking for IUI, which means that they had no intense causes of infertility which made the IUI not a choice of treatment. Factors cause secondary infertility are less severe than those cause primary male infertility which can result from a variety of conditions included hypothalamo-pituitary disorders, systemic disorders, chronic illnesses, nutritional deficiencies and congenital disorders $[12,13]$. A multicenter study reported that chromosomal abnormalities are common in infertile men mostly those with primary infertility, with an incidence of $5.8 \%$ as compared to an incidence of $0.5 \%$ in the fertile population [14].

A relatively high incidence of asthenozoospermia could be observed in the immunologically infertile males, because antisperm antibodies may be sustained and enhanced through bacterial or viral infections, subsequently they may severely alter spermatogenesis $[3,15,16]$. The different causes of male infertility support the results of this study because the causes of primary infertility are more intense in their effects than that of the secondary infertility, and need more sophisticated ways of ART other than IUI [10]. 


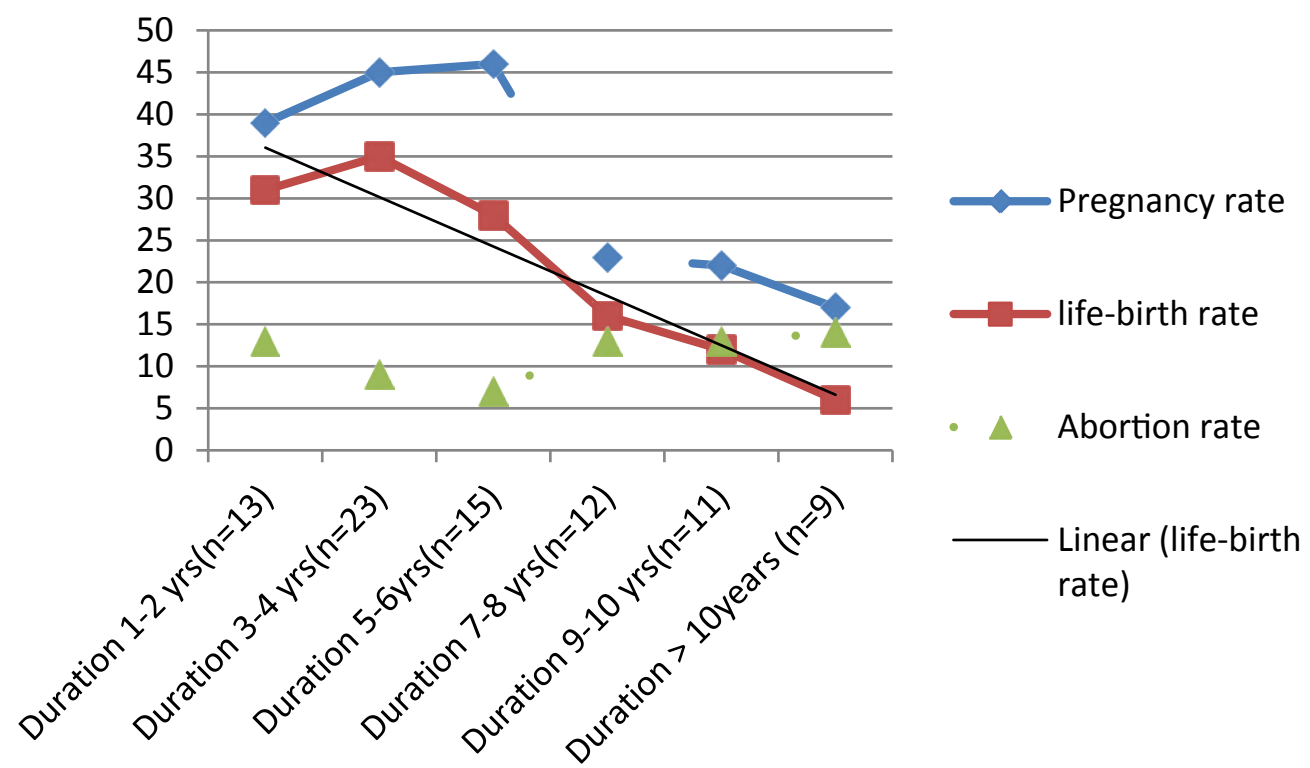

Figure 5 Relationship between duration of infertility and ART outcomes (pregnancy, life-birth rates) after IUI, among Iraqian infertile males.

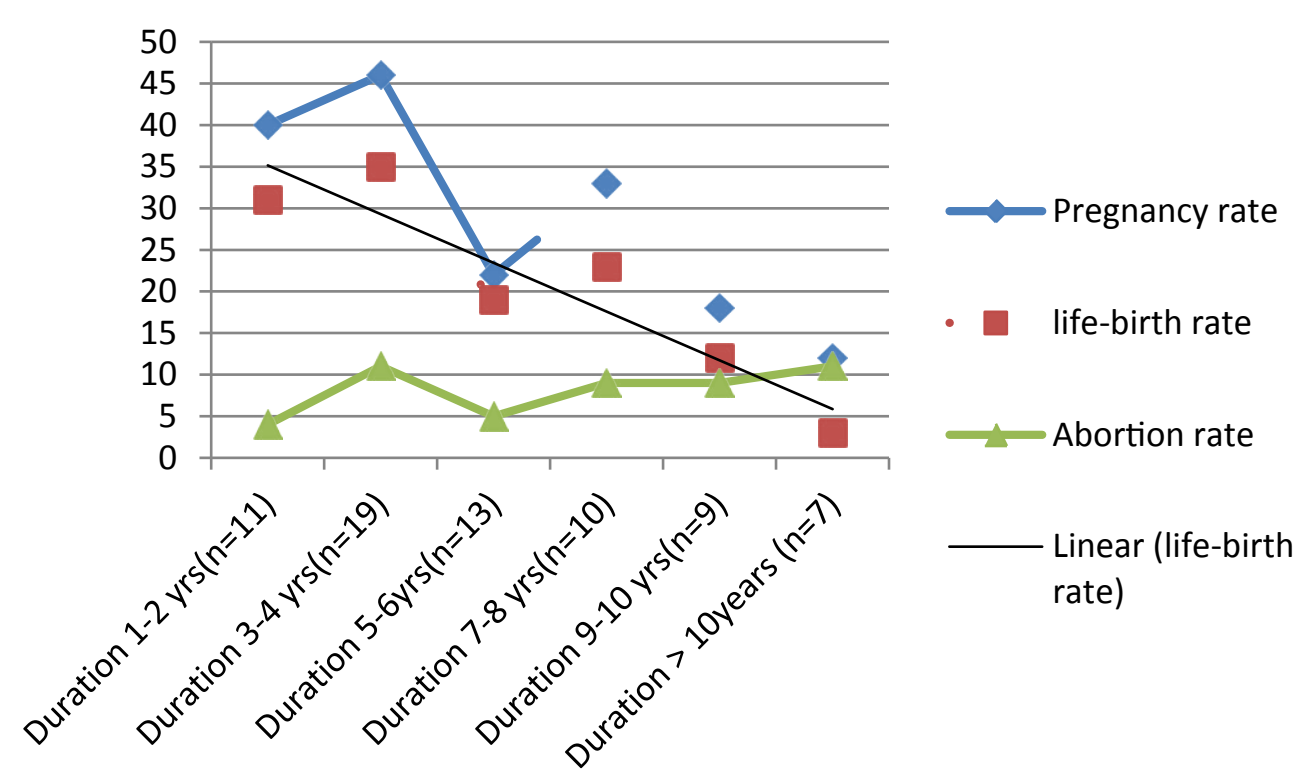

Figure 6 Relationship between duration of infertility and ART outcomes (pregnancy, life-birth rates) after IUI, among Yemini infertile males.

In infertile males with secondary infertility in addition to the previous causes, varicose veins and number of environmental factors including high temperature, inflammatory factors, social habits, drugs, radiation therapy and xenobiotics (pesticides, insecticides) had been shown to have negative impact on testicular function but had been implicated in the decline of sperm quality [17].

The groups of the infertile males with history of infertility of 3-4 years duration are largest groups who attended medical services, in contrast infertile males with history of infertility $\geq 10$ years were the smallest group. As the duration of infertility increases, the couples become less interested to seek the medical services. Besides, the psychological factors (depression and hopelessness) play a major role in these cases [1].

Intra-uterine insemination is practicing widely as an empirical treatment for male factor infertility and as a mean to bypass defects in sperm-cervical mucus interaction [18]. In the present study IUI was performed for 152 couples with mild male factor infertility. Studying the results of this study, the positive IUI outcome was observed in groups who had post-activation sperm parameters of more sperm progressive motility percentage grade $(A)$ and grade $(B)$ and higher percentage of normal sperm 
morphology as well as less sperm concentration. The sperm quality that is necessary for successful IUI is lower than WHO threshold values of normal sperm. IUI is an effective therapy for male factor infertility when initial sperm motility is $\geq 30 \%$ and the total motile sperm count is $\geq 5$ million, when the initial values are lower IUI has little chance of success [19]. An average total motile sperm count of 5 million may be a useful threshold value for decision about treating a couple with IUI or IVF [20]. The final post- washed sperm count used for IUI may be considered predictive of the success for pregnancy and allow couples to be informed of the chances of success. Pregnancy rates were significantly higher among couples with more than (14\%) normal sperm morphology than among those of sperm morphology was less than (14\%) normal sperm morphology [1, 21].

The greatest enthusiasm supports IUI is when combined with Controlled Ovarian Hyperstimulation $(\mathrm{COH})$ that increases the number of oocytes ready for fertilization. IUI combined with superovulation may increase monthly probability of pregnancy approximately four times compared to that following IUI timed by LH surge [22]. According to the largest available clinical studies, IUI in stimulated cycles with conventional doses of gonadotropin, induce pregnancy in $10-15 \%$ of cases with better results in couples with normal sperm parameters [23]. The use of an ovulation induction agent, clomiphene citrate, human Chorionic Gonadotropin (hCG) or Human Menopausal Gonadotropin (HMG), increases the success rate of IUI by $10 \%$ [3].

The timing of insemination in IUI programmers in relation to other major events around ovulation or most probably ovulation itself has been suggested as the most important variable affecting the success of this treatment [24]. In addition timing of insemination, number of insemination per cycle may influence the ultimate pregnancy [22]. To maximize the chance of success of IUI, the timing of insemination needs to be closely related to the time of ovulation, ovulation occurred at a mean time of 27.3 hour from onset of LH surge [25].

The normal physiological activity of the reproductive organs gradually decreases with advancing age due to irreversible abnormal physiological changes in the testes that affect the fertilization potential of human spermatozoa. Semen quality, frequency of ejaculation and sperm functions gradually decrease with advancing age. Moreover, the spermatozoa from older men have increased incidence of abnormalities and many children born from older men have an increased chance of abnormalities [26].

With increment duration of infertility, the infertile males become less interested in seeking the medical services. Depression and hopelessness play a major role in those cases. An increment in the duration of infertility to more than 10 years results in reduction in the testicular blood supply especially in the older infertile males and this affects the normal physiology of the testes and epididymis which results in marked elevation of the serum FSH and LH levels [27]. Furthermore there is an increase in the number of pathological spermatozoa which linked to an increase in both age and duration of infertility [18]. Therefore, in this study least positive IUI with 10 years duration of infertility and age $\geq 50$ years.

The success of IUI is very strongly tied to precise adherence to proven methods for everything from preparing the sperms to inseminating the lady. The factors that may influence the results of IUI, age of the couples and duration of infertility, final postactivation sperm parameters, method of preparing the semen, type and composition of the culture media, $\mathrm{COH}$ protocols, timing of IUI and accurate selection of couples for IUI with experience of the physician in performing the insemination. In 2010, a study of pregnancy rates after performed at infertility centers; it was found that unsuccessful outcomes often were attributed to physician error and a lack of familiarity with procedure [24].

Present study shows a negative relationship between the duration of infertility and outcome of ART include pregnancy and life-birth rates. That is in a good agreement with that study published by Glazener et al. [28]. The researchers of the present work conclude that by increase in the duration of infertility the outcome of assisted reproductive techniques -IUI in infertile male will decrease markedly. For further study the researchers recommend the following:

1. Study the hormonal imbalance in patient with male factor infertility that could be appeared in late inability to achieve pregnancy.

2. Improve the cultural fertility educations of couples whose cannot be parents within 2 years regular unprotected intercourse.

3. Make psychological preparation of patients with duration of infertility more than 8 years before their involvement in the ART. 


\section{References}

1 Allow AK, Rashad AAT, Saeed MS, Bracamonte MA (2009) Life-Birth Rate Following Metformin Mono-Therapy in mono-Cycle Anavulatory Yemeni Infertile Women with Polycystic Ovarian Syndrome-PCOS. Benha MJ 26: 325-341.

2 Dick ML, Bain CJ, Purdie DM, Siskind V, Molloy D, et al. (2003) Selfreported difficulty in conceiving as a measure of infertility. Hum Reprod 12: 2711-2717.

3 Allow AK, Rashad AAT, Saeed MS, Bracamonte MA (2009) Is Antisperm Antibodies Lab investigation Technique Necessary as a Routine Examination for Diagnosis of Immunoinfertility? Benha MJ 26: $343-358$

4 Wendy Y, Sanjay C (2005) Diagnostic Evaluation and Treatment of the Infertile couple. In: Bruce Richard E, Ricardo A (eds.) Essential Reproductive Medicine, Blackwall McGrow-Hill, pp: 15: 359-392.

5 Jensen $M$, Leffers $H$, Petersen $J H$, Nyboe Andersen $A$, Jørgensen $\mathrm{N}$, et al. (2004) Frequent polymorphism of the mitochondrial DNA polymerase gamma gene in patients with normal spermiograms, and unexplained subfertility. Hum Reprod 1: 65-70.

6 Campbell S, Monga A (2000) Infertility investigation. In: Campbell S, Monga A (eds.) Textbook of Gynecology by Ten Teatures (1 $17^{\text {th }}$ edn.) Arnold, Euston Road, London, p: 88.

7 Petrozza JC, Lucidi RS (2006) Assisted Reproduction Technology. eMedicine Specialties/ Medicine. Ob/Gyn, Psychiatry and Surgery.

8 Sylvia S, Mader (2005) Birth control and infertility. In: Sylvia S and Mader (eds.) Human Reproductive Biology ( $3^{\text {rd }}$ edn.). McGraw-Hill McGraw-Hill, pp: 142-156.

9 WHO (2002) Manual on basic semen analysis final version. ESHRE 03-11.

10 Jawad MA (2008) Assessment of changes in reproductive hormones and clomiphene citrate challenge test for evaluation of the outcome of intra-uterine insemination of infertile females. Master of Science thesis in Applied Embryology. Institute of Embryo Research and Infertility treatment/AI-Nahrain University.

11 Al-Zubaidi UIM (2008) Comparative study on the effects of Sildenafi citrate treatment on parameters of human and mice spermatozoa. Master of Science thesis in Applied Embryology, Institute of Embryo Research and Infertility Treatment, University of Al-Nahrin, Iraq.

12 Khorram O, Patrizio P, Wang C, Swerdloff R (2001) Reproductive technologies for male infertility. JCEM 86: 2373-2379.

13 Gangel KE (2002) Practice Guidelines AUA and ASRM produce recommendations for male infertility. J AFP 65: 5289-2590.
14 Madoro MR, Kirk CL, Chuang WW, Lamp DJ (2003) Genes and male infertility: What can go wrong? J Androl 24: 465-489.

15 Shibahara H, Shiraishi $\mathrm{Y}$, Hirano $\mathrm{Y}$, Suzuki T, Takamizawa S, et al. (2003) Diversity of the inhibitory effects on fertilization by antisperm antibodies bound to the surface of ejaculated human sperm. Hum Reprod 18: 1469-1473.

16 Kurpisz KM (2004) New approaches to male infertility: forum introduction. Reprod Bio Endo 2: 1-2.

17 Juan GA (2003) Nurture vs. nature: How can we optimize sperm quality? J Androl 24: 640-648.

18 Wang CW, Horng SG, Chen CK, Wang HS, Huang HY, et al. (2008) Ovulation induction with tamoxifen and alternate-day gonadotrophin in patients with thin endometrium. Reprod Biomed 17: 20-26.

19 Sloboda DM, Hickey M, Hart R (2010) Reproduction in females: the role of the early life environment. Human Reproduction Update 17: 210-227

20 Mancini T, Casanueva FF, Giustina A (2008) Endocrinology \& Metabolism Clinics of North America. Metabolism Clinics 37: 45-51.

21 Loutradis D, Vomvolaki E, Drakakis P (2008) Poor responder protocols for in-vitro fertilization: options and results. Curr Opin Obstet Gynecol 20: 374-378.

22 De Sutter P, Veldeman L, Kok P, Szymczak N, Van der Elst J, et al. (2005)Comparison of outcome of pregnancy after intra-uterine insemination (IUI) and IVF. Hum Reprod 20: 1642-1646.

23 Crosignani PG, Somigliana E (2007) Effect of GnRH antagonists in FSH mildly stimulated intra-uterine insemination cycles: a multicenter randomized trial. Hum Reprod 22: 500-507.

24 Cooper TG, Noonan E, von Eckardstein S, Auger J, Baker HW, et al. (2010) World Health Organization reference values for human semen characteristics. Human Reproduction 16: 231-245.

25 Ikechebelu Jl, AdinmaJl, Orie EF, Ikegwuonu SO (2003) High prevalence of male infertility in southeastern Nigeria. Journal of Obstetrics \& Gynaecology 23: 657-659.

26 Ramezanzadeh F, Aghssa MM, Abedinia N, Zayeri F, Khanafshar N, et al. (2004) A survey of relationship between anxiety, depression and duration of infertility. BMC Women's Health 10: 1-7.

27 Roupa Z, Polikandrioti M, Sotiropoulou P, Faros E, Koulouri A, et al. (2009) Causes of infertility in women at reproductive age.Hsj-Health Science Journal 3: 80-87. 3: 80-87.

28 Glazener MA, Ford WC, Hull MG (2000) The prognostic power of the post-coital test for natural conception depends on duration of infertility. Human Reprod 15: 1953-1957. 